\title{
Unilateral left paramedian infarction of thalamus and midbrain: a clinico-pathological study
}

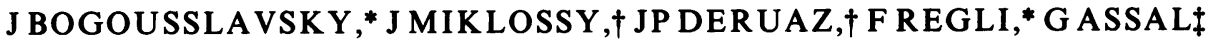 \\ From the Department of Neurology, ${ }^{*}$ Division of Neuropathology, $\dagger$ and Centre of Neuropsychology, $\ddagger$ Centre \\ Hospitalier Universitaire Vaudois, Lausanne, Switzerland
}

SUMMARY In a patient with a unilateral embolic infarct in the left posterior thalamo-subthalamic paramedian artery territory, neuropathological studies showed involvement of the intralaminar, dorsomedial, and internal part of the ventral posterior nuclei of the thalamus, of the rostral part of the mesencephalic reticular formation, and of the posterior commissure. The patient showed upgaze palsy for voluntary saccades, smooth pursuit and vestibulo-ocular movements, sustained downgaze, right-sided motor hemineglect and facio-brachial hypaesthesia, motor transcortical aphasia and anterograde amnesia. This case confirms that unilateral destruction of the posterior commissure, rostral interstitial nucleus of the MLF and interstitial nucleus of Cajal produces a non-dissociated upgaze palsy. Involvement of the nucleus of Cajal probably produced the sustained downward deviation of the eye, by causing predominance of downward vestibulo-ocular inputs. This case also shows that thalamic aphasia and anterograde amnesia may be related to a paramedian lesion of the thalamus, with special reference to involvement of the dorsomedial nucleus, in the absence of lesion of the pulvinar and mamillo-thalamic tract and of conspicuous involvement of the ventral lateral nucleus. Selective hemineglect for motor tasks may occur in infarction of the dominant thalamus, involving the intralaminar nuclei.

Unilateral infarct of the thalamus and/or midbrain is unusual and pathologically proven cases are uncommon in the literature. ${ }^{1-13}$ In these reports, clinical data are often lacking and in many cases, it is difficult to establish clinico-anatomic correlations. We have studied a patient with complex disturbances of vertical movements and neuropsychological impairment, who died 2 weeks after onset of the symptoms. At necropsy, there was a recent unilateral infarct involving the paramedian part of the thalamus and upper midbrain on the left side.

\section{Case report}

A 72-year-old right-handed housewife was admitted after she suddenly experienced right-sided weakness and speech disturbances. Seven years before, she had a right mammectomy for a breast cancer, and 6 months before admission she suffered an inferolateral myocardial infarct. On admission, the patient was slightly drowsy, disorientated in time

Address for reprint requests: J Bogousslavsky, Service de Neurologie, CHUV, 1011 Lausanne, Switzerland.

Received 26 February 1985 and in revised form 12 August 1985. Accepted 25 August 1985 and place, and showed the speech disturbances described below. On cranial nerves examination, except the oculomotor disturbances, the patient showed tactile and thermo-algesic hypaesthesia of the right side of the face, and a moderate right central facial paresis. The visual fields were complete, with no visual neglect on simultaneous presentation of visual stimuli in the temporal fields. A slight proximal paresis of the right upper and lower limbs was present, without hyperactive tendon reflexes or Babinski's sign. The patient did not spontaneously use her limbs on the right side, although she could move them perfectly under sustained verbal stimulation. Withdrawal to pain was absent on that side, although the patient reported that she could feel a painful sensation (despite the slight decrease of superficial sensation in this side of the body). Also, she did not maintain the right arm extended more than 4-5 seconds, and did not adequately place this arm when resting in bed, leaving it aside in inappropriate and uncomfortable positions. A slight decrease of tactile and algesic sensation was present in the right upper limb and trunk down to D10, without sensory extinction on simultaneous tactile stimulation of both sides of the body. Postural and vibratory sensation was normal. The gait was not evaluated. The blood pressure was $180 / 120 \mathrm{mmHg}$, with pulsations of $84 /$ minute. General examination was normal.

Oculomotor findings In primary position, the patient showed sustained conjugate downward deviations of the 
eyes, with a very slight inward deviation. A very slow elevation of the eyes was possible from this downward position, on voluntary and smooth pursuit movements, but with a maximal amplitude of $10^{\circ}-15^{\circ}$. No upward saccade could be elicited. No movement was produced on vertical oculocephalic manoeuvre (with Frenzel glasses). Caloric testing not performed. Abduction of the right eye was limited on voluntary and smooth pursuit movements (with diplopia), but a full range deviation could be obtained on horizontal oculocephalic manoeuvre. Vertical optokinetic responses were abolished (optokinetic drum, $20^{\circ}-40^{\circ} / \mathrm{s}$ ). Horizontal optokinetic responses were normal. Convergence could not be elicited voluntarily or on pursuit attempts. The right pupil showed a relative miosis $(1.5 \mathrm{~mm}$, vs $2 \mathrm{~mm})$, with weak direct and consensual reactions on both sides. These findings did not change before the patient died.

Neuropsychological findings Only a partial assessment was realised, because the patient died unexpectedly 2 weeks after admission. On admission, the patient was disorientated in time and place. Her speech was reduced, non-fluent, with frequent pauses and decreased volume of the voice. She made semantic and less often phonemic paraphasias. Repetition of words, non-words and sentences (up to 15 words) was preserved. Verbal comprehension was normal for simple orders but was impaired for complex orders (Pierre Marie's three papers). No buccolingual apraxia was noted. The motor neglect of the right upper and lower limbs has been described with the neurologic findings. Thirteen days later, the patient underwent a more detailed neuropsychological examination. She was slightly apathetic but not drowsy and she collaborated well but was still disorientated in time and place. Spontaneous speech was still reduced and the sentences were very rarely formed by more than three to four words. No echolalia was present. Verbal comprehension was good even for complex orders (Pierre Marie's three papers, Token test), but the patient frequently interrupted the execution of a task before its completion. Repetition of words (1-8 phonemes), non-words and sentences (3-15 words) was normal. Verbal automatic series (weekdays, months) were correctly realised anterogradely, but retrograde naming showed perseverations. Naming was deficient on Boston Naming test (21 correct answers/76), with either anomia or semantic paraphasias. The reading of letters was good, but the patient was unable to read a text, because of diplopia and production of semantic paralexias. She could perfectly transpose into sentences a text spelled by the examiner. Spelling showed numerous errors. The patient was not able to write or draw, because she did not initiate the movement of the right hand. Oral calculation was impossible because of difficulties in recalling the numbers. Visuo-spatial recognition was impaired (Ghent: 29 correct answers/36, Poppelreuter $1 / 4$, inadequate geographic orientation on a map). The patient was unable to recall any events which had happened to her after the onset of her stroke, and she could not recall what she had been doing minutes, hours, or days before the examination. Events that had happened a few months or years before were adequately recalled despite the speech disturbances. Learning of series of 3-10 words was impossible: the patient recalled none or only one of the words even after five trials. Sometimes, perseveration of one word from a preceding series occurred. These marked difficulties for verbal learning were confirmed on Hebb's re- curring digits (maximal span: 2, failure of span +1 learning). A similar impairment of visual learning was also observed on Corsi's block-tapping (maximal span of 3, failure of span +1 learning). During these tests, the patient remained attentive and did not show distractibility.

Laboratory findings Chest radiographs, standard blood and urine tests were normal (except a thrombocytosis of 600 $\left.\times 10^{9} / 1\right)$. ECG showed widespread ischaemic changes and signs of the ancient inferolateral infarct. An EEG made 10 days after admission was normal, except for episodic theta waves in the left premotor region. Two CT scans showed a paramedian hypodense area in the left thalamus, with slight enhancement after intravenous injection of contrast medium, and with normal ventricular size. CSF was normal, with a pressure (lumbar) of $13 \mathrm{~mm} \mathrm{H}_{2} \mathrm{O}$. Doppler ultra sonography with spectrum frequency analysis did not show extracranial stenosis. Somatosensory evoked potentials were normal bilaterally (median nerve stimulation).

Evolution The patient was put on intravenous heparin therapy $(30,000 \mathrm{U} / 24 \mathrm{~h})$. After 10 days, this therapy was replaced by subcutaneous heparin $(2 \times 5000 \mathrm{U} / 24 \mathrm{~h})$ and acetylsalicylic acid by mouth $(1 \mathrm{~g} / 24 \mathrm{~h})$. Fourteen days after admission, while resting in bed, the patient suddenly fell in deep coma, with intermittent apnea and unmeasurable blood pressure. She could not be resuscitated and died after 10 minutes.

\section{Pathological findings}

Necropsy showed generalised atherosclerosis, multiple recent and old myocardial infarcts without intracardiac thrombus, thrombosis of the left femoral vein, and pulmonary emboli (the probable cause of death). The liver con-

Table 1 Involvement of thalamic and mesencephalic structures related to the symptomatology of our patient

\begin{tabular}{lcc}
\hline & left side & right side \\
\hline Ventral lateral nucleus & + & - \\
Dorsomedial nucleus & +++ & - \\
Centromedian nucleus & ++++ & - \\
Parafascicular nucleus & ++++ & $(+)$ \\
Paracentral nucleus & ++++ & - \\
Central medial nucleus & ++++ & - \\
Lateral posterior nucleus & + & - \\
Ventral posterolateral nucleus & + & - \\
Ventral posteromedial nucleus & ++++ & - \\
Nucleus reuniens & ++++ & - \\
Subthalamic nucleus & +++ & - \\
Mamillotegmental tract & +++ & - \\
Zona incerta & +++ & - \\
Field H of Forel & +++ & - \\
Lenticular fasciculus & +++ & - \\
Thalamic fasciculus & +++ & - \\
Nucleus ruber & ++ & - \\
Fasciculus retroflexus & ++++ & - \\
Central tegmental tract & ++++ & - \\
Medial longitudinal fasciculus & + & - \\
Rostral interstitial nucleus of MLF & (rostral part) & \\
Interstitial nucleus of Cajal & ++++ & - \\
& ++ & - \\
Nucleus of Darkschewitsch & (rostral part) & \\
Nucleus of posterior commissure & ++ & - \\
Posterior commissure & ++++ & - \\
\hline Thenumber of plus signs ( & ++++ & - \\
\hline
\end{tabular}

The number of plus signs ( + ) reflects the severity of the lesions. - :no lesion. 
tained many metastases from the breast carcinoma operated 7 years before. Gross examination of the brain (weight 1230 g) showed only mild atherosclerosis of the circle of Willis.

The sections of the brain showed an isolated macroscopical finding: a paramedian infarct in the left thalamus and in the subthalamic region $(1,7 \times 0,8 \mathrm{~cm})$, extending from the level of the mamillo-thalamic tract to the periaquaeductal gray matter (fig 1). This partly haemorrhagic infarct was situated in the territory of the posterior thalamosubthalamic paramedian artery. Fragments of the brain were submitted for microscopic examination of the right central circonvolution, left central circonvolution, left inferior parietal circonvolution, left superior parietal and left supramarginal circonvolution, right parietal region, left parieto-occipital region, and medulla oblongata. The blocks were embedded in paraffin and cut at $10 \mu \mathrm{m}$ sections. They were stained with haematoxylin-eosin, crezyl violet, Loyez and van Gieson luxol fast blue (myelin stain), Holzer stain and PTAH, van Gieson elastin, Perl's prussian blue, periodic acid Schiff, Congo Red. Blocks comprising thalami, subthalamic regions, midbrain and pons were studied in 312 serial sections and stained alternatively with haematoxylin and eosin and Loyez stain. Further frozen sections (after passage in sucrose) of blocks from the right and left pre and postcentral gyrus were stained with crezyl violet, Bodian and Glees stain (for axons) and Schroeder stain (myelin stain). Microscopic study of the left thalamo-mesencephalic infarct showed several haemosiderin-laden macrophages, astrocytic gliosis, neovessels and axonal swellings. Some small vessels within the infarct were occluded by emboli.

The rostral extremity of the softening was situated at the level of the mamillo-thalamic tract, where two areas of infarction in the dorsomedial nucleus were present, without involvement of the mamillo-thalamic tract (fig 2). The infarct destroyed the medial rostral part of the cerebral peduncle and fibres of the mamillo-tegmental tract near their origin. The serial sections revealed a well delineated infarction in the dorsal part of dorsomedial nucleus, the centromedian nucleus, parafascicular, paracentral nuclei, the nucleus reuniens, the ventral posteromedial nucleus (VPM), the medial part of the ventral posterolateral nucleus (VPL), a small part of the posterior portion of the ventral lateral nucleus (VL), and a large part of the subthalamic nucleus (table 1, fig 2). More caudally the medial-rostral part of the red nucleus and the central gray matter of the third ventricle at the level of the rostral interstitial nucleus of MLF were involved. The fasciculus retroflexus and the fibres of the central tegmental tract were also destroyed, as the field $\mathrm{H}$ of
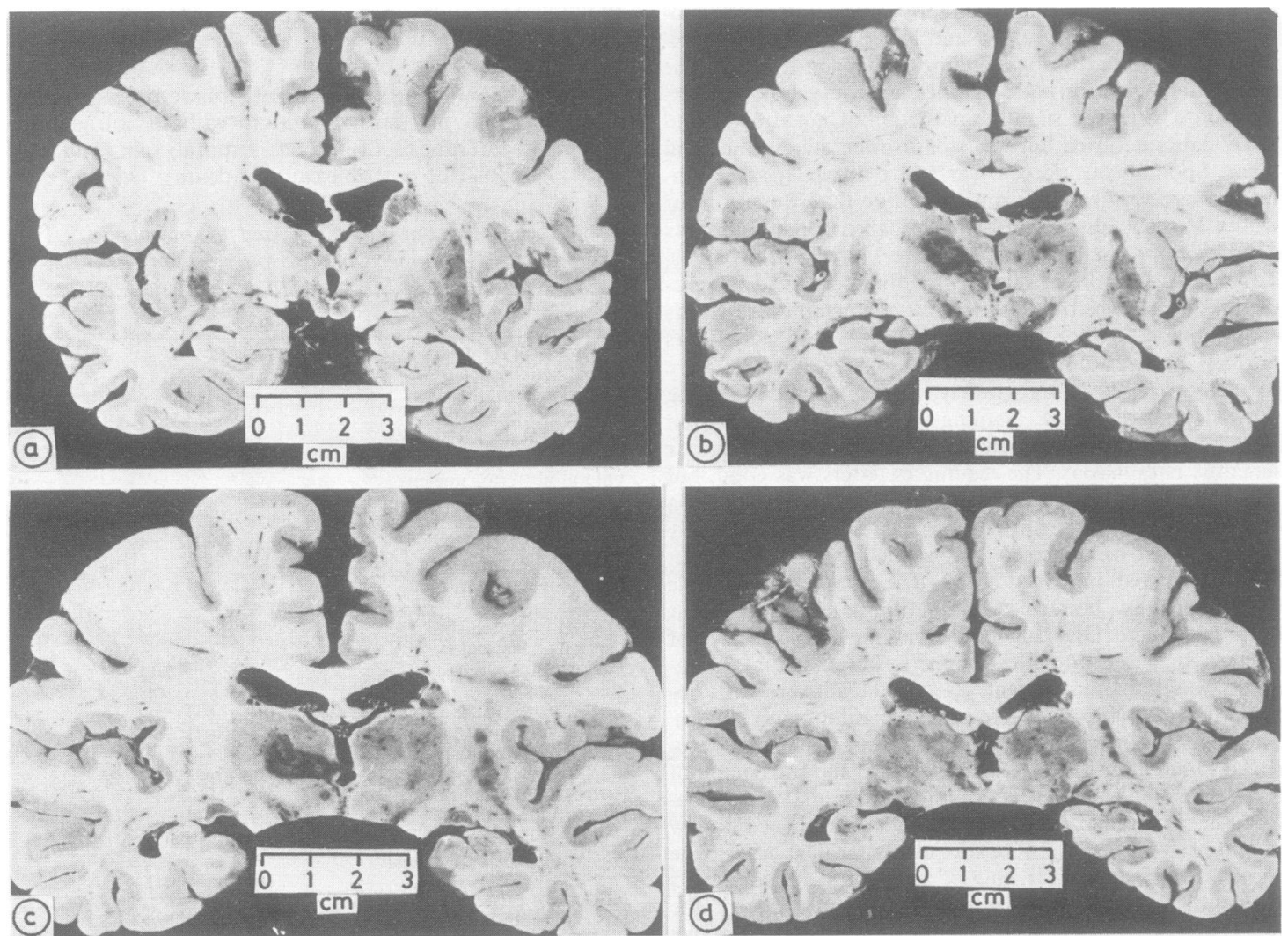

Fig 1 Coronal sections showing a sharply defined infarct in the territory supplied by the left posterior thalamo-subthalamic paramedian artery. 
Forel, the thalamic fascicle and fibres of the ansa lenticularis. Caudally, the infarct involved the left part of the posterior commissure, sparing some ventrocaudally crossing fibres. The pulvinar was not involved. The caudal end of the lesion was situated at the level of the posterior commissure (PC): the whole rostral interstitial nucleus of MLF (riMLF), the rostral half of the interstitial nucleus of Cajal (iC) and of the nucleus of Darkschewitsch (nD) were involved (fig 3), as well as the most rostral fibres of the left MLF. The oculomotor nuclei, their roots, and the remainder of the brainstem were intact. The right thalamus did not show any significant lesion (an area of focal demyelination of a few $\mu \mathrm{m}$ was demonstrated in the parafascicular nucleus). Rare minute recent infarcts measuring a few $\mu \mathrm{m}$, probably secondary to emboli, were seen in the central region of both hemispheres. In order to detect any axonal degeneration in layer IV and a possible neuronal loss or degeneration in layer VI (the lamina of origin of most cortico-thalamic fibres) in the somatosensory cortex due to lesions in the VPM, serial sections of small tissue blocks, taken in areas 4, 3,1 and 2 of both hemispheres, were examinated with special techniques, ${ }^{14} 15$ and showed degenerated fibres.

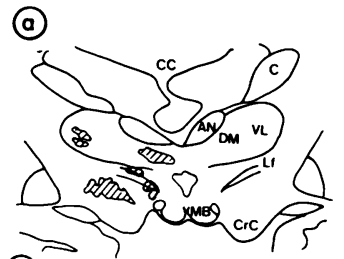

(c)
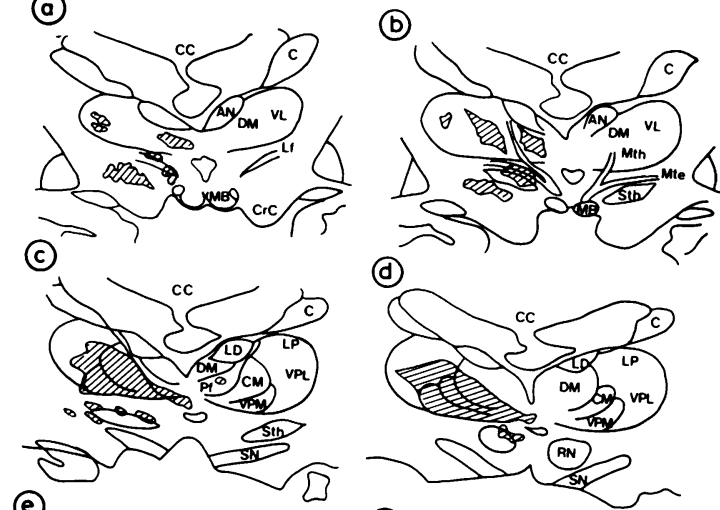

(d)
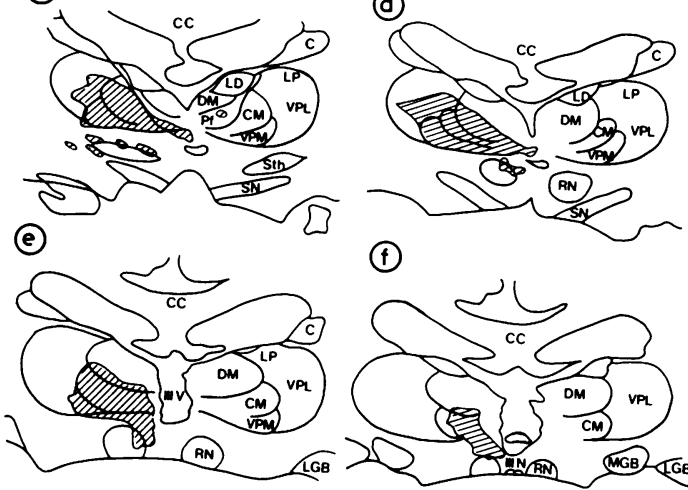

(f)

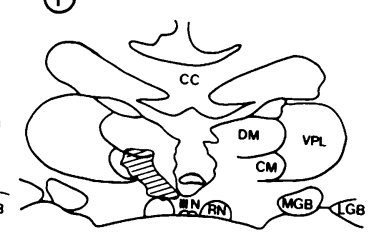

Fig 2 Camera lucida drawings of transverse coronal sections through the thalamus. $C C=$ corpus callosum, $c=$ caudate nucleus, $M B=$ mamillary body, $M t h=$ mamillo-thalamic tract, Mte = mamillo-tegmental tract, $L f=$ lenticular fascicle, $I I I V=$ third ventricle, $\mathrm{CrC}=\mathrm{crus}$ cerebri, $A N=$ anterior nucleus, $D M=$ dorsomedial nucleus, $C M=$ centromedian nucleus, $P f=$ parafascicular nucleus, $L D=$ lateral dorsal nucleus, $L P=$ lateral posterior nucleus, $V L=$ ventral lateral nucleus, $V P L=$ ventral posterolateral nucleus, $V P M=$ ventral posteromedian nucleus, Sth $=$ subthalamic nucleus, $R N=$ red nucleus, $S N=$ substantia nigra, $M G B=$ medial geniculate body, $L G B=$ lateral geniculate body, III $N=$ oculomotor nuclei, $P C=$ posterior commissure.

\section{Discussion}

The thalamo-mesencephalic infarct was related to proven emboli in the posterior thalamo-subthalamic paramedian artery. These emboli probably arose from the heart, which showed recent myocardial infarcts.

The slight right-sided weakness probably corresponded to involvement of the ansa lenticularis, and the decrease of superficial sensation in the right upper part of the body down to D 10 was related to involvement of the ventral posteromedial nucleus (face) and of the internal part of the ventral posterolateral nucleus (upper limbs, upper trunk).

A non-dissociated upgaze palsy was present, with permanent downward deviation of the eyes. In the midbrain, the infarct was strictly unilateral and involved the riMLF iC, $\mathrm{nD}, \mathrm{PC}$, as well as the red nucleus, zona incerta, tegmental $\mathrm{H}$ field and fasciculus retroflexus tract. Classically, bilateral lesions in the
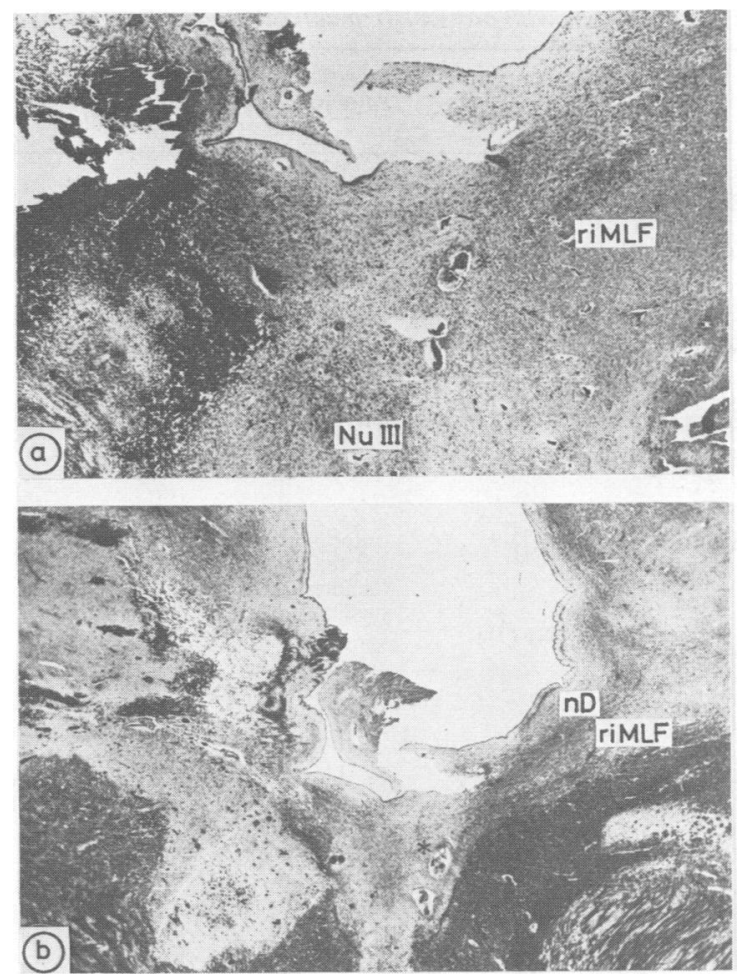

Fig 3 (A) Transverse section through level of oculomotor nuclear complex (NU III) (approximately corresponding to that of fig $2 F$ ). Asterisk points to right posterior

thalamo-subthalamic paramedian artery. Note that on the left side the riMLF is entirely destroyed. (PAS stain; $\times 2$ ).

$(B)$ Section parallel to that shown in $(A)$. riMLF and $n D$ can be recognised because of their relatively high content of myelinated fibres. (Loyez stain; $\times 2$ ). 
upper midbrain have been reported in vertical gaze palsy. ${ }^{101316-18}$ However, upgaze palsy, which was initially described by Henoch ${ }^{19}$ and Parinaud, ${ }^{20}$ has been associated with a presumed ${ }^{21-23}$ or proven $^{28101324-26}$ unilateral mesencephalic lesion in a few cases. The cases of upgaze palsy with a proven unilateral infarct of the upper midbrain are summarised in table 2 . The $\mathrm{iC}$ and $\mathrm{nD}$ were involved in the four reported cases and in our case. In the first three cases, the riMLF was not described, but it appears from the pathologic studies that it was very probably damaged; it was involved in another case ${ }^{13}$

Table 2 Cases with upgaze palsy from a proven unilateral midbrain infarct

\begin{tabular}{|c|c|c|c|}
\hline & Lesion (midbrain)* & downward deviation & Vertical oculocephalic manoeuvre \\
\hline $\begin{array}{l}\text { Freund, } 1913(2) \\
\text { Balthasar and Hopf, } 1966(28) \\
\text { Hatcher and Klintworth, } 1966(8) \\
\text { Christoff, } 1974(10)\end{array}$ & $\begin{array}{l}\mathrm{nD}, \mathrm{iC}, \mathrm{FR} \\
\text { sparing of PC? } \\
\mathrm{nD}, \mathrm{iC} \text {, degeneration of } \mathrm{PC} \\
\text { "from the superior colliculus into the } \\
\text { pretectum post the } \mathrm{PC} \text { and caused } \\
\text { demyelination to it" }\end{array}$ & $\begin{array}{l}- \\
-\end{array}$ & $\begin{array}{l}\text { preserved } \\
\text { vertical deviations } \\
\text { no deviation } \\
?\end{array}$ \\
\hline $\begin{array}{l}\text { Pierrot-Deseilligny et al, } \\
1982 \text { (13)/Serdaru et al, } 1982 \text { (27) } \\
\text { Present case }\end{array}$ & $\begin{array}{l}\mathrm{nD}, \mathrm{iC}, \mathrm{FR} \text {, upper MLF } \\
\text { demyelination of } \mathrm{PC} \\
\mathrm{nD}, \mathrm{iC}, \mathrm{FR} \text {, riMLF, PC }\end{array}$ & $\begin{array}{l}\text { intermittent } \\
\text { sustained }\end{array}$ & $\begin{array}{l}\text { preserved } \\
\text { vertical deviations } \\
\text { no response from } \\
\text { downward deviations }\end{array}$ \\
\hline
\end{tabular}

nD: nucleus of Darkschewitsch, iC: nucleus interstitialis of Cajal, riMLF: rostral interstitial nucleus of the MLF, PC: posterior commissure, FR: fasciculus retroflexus.

*In the 3 first cases the riMLF was not described.

Table 3 Cases with proven left unilateral paramedian infarct of the thalamus

\begin{tabular}{|c|c|c|c|c|}
\hline & $\begin{array}{l}\text { Involvement of } \\
\text { paramedian nuclei }\end{array}$ & $\begin{array}{l}\text { Involvement of other } \\
\text { thalamic nuclei or } \\
\text { connections }\end{array}$ & Associated lesions & $\begin{array}{l}\text { Neuropsychological } \\
\text { disturbances }\end{array}$ \\
\hline $\begin{array}{l}\text { Freund, } 1913(2) \\
\text { Balthasar and Hopf, } 1966(28)\end{array}$ & pf, dm & - & $\begin{array}{l}\text { midbrain (left), } \\
\text { pyramidal tracts } \\
\text { in the brainstem }\end{array}$ & somnolence \\
\hline Chiray et al, 1923 (3) & "paramedian nuclei' & $\begin{array}{l}\text { dorsocaudal part } \\
\text { of the thalamus }\end{array}$ & $\begin{array}{l}\text { subthalamic area, } \\
\text { cerebellar peduncle } \\
\text { hippocampus, frontal } \\
\text { cortex }\end{array}$ & not mentioned \\
\hline Molnàr, 1959 (6) & $\begin{array}{l}\text { 'paramedian nuclei' } \\
\text { (with cm) }\end{array}$ & Tmth & $\begin{array}{l}\text { midbrain (left), } \\
\text { scattered lesions in the } \\
\text { right cerebral hemisphere }\end{array}$ & $\begin{array}{l}\text { verbal perseverations, literal } \\
\text { and verbal paraphasias, } \\
\text { alexia, agraphia }\end{array}$ \\
\hline $\begin{array}{l}\text { Gruner and Feuerstein, } 1966 \text { (7) } \\
\text { Case B }\end{array}$ & $\mathbf{c m}$ & - & $\begin{array}{l}\text { midbrain (bilateral), } \\
\text { cerebral hemispheres }\end{array}$ & not mentioned \\
\hline Case S & 'paramedian nuclei' & - & $\begin{array}{l}\text { mesencephalic tegmentum } \\
\text { and red nucleus (left) } \\
\text { cerebral hemispheres }\end{array}$ & 'sudden coma' \\
\hline $\begin{array}{l}\text { Castaigne et al, } 1981 \text { (71) } \\
\text { Case } 9\end{array}$ & pf, dm, cm & vl, pu & lacunae & $\begin{array}{l}\text { agitation, incoherence, } \\
\text { confusion, disorientation in } \\
\text { time and place }\end{array}$ \\
\hline Case 19 & $\mathrm{pf}, \mathrm{dm}, \mathrm{cm}$ & $\begin{array}{l}\text { anterior part of the } \\
\text { ventrolateral region } \\
\text { Tmth, pu }\end{array}$ & $\begin{array}{l}\text { right anterior cerebral } \\
\text { infarct }\end{array}$ & unknown \\
\hline Case 22 & $\mathrm{pf}, \mathrm{dm}, \mathrm{cm}$ & $\begin{array}{l}\text { anterior part of the } \\
\text { ventrolateral region } \\
\text { Tmth }\end{array}$ & $\begin{array}{l}\text { bilateral middle } \\
\text { cerebral infarct, lacunae }\end{array}$ & unknown \\
\hline $\begin{array}{l}\text { Case } 26 \\
\text { Davous et al, } 1984(72)\end{array}$ & $\begin{array}{l}\text { pf, dm, cm } \\
\text { pf, dm, cm }\end{array}$ & $\begin{array}{l}\text { vlm, vlo } \\
\text { vlm }\end{array}$ & $\begin{array}{l}\text { midbrain (bilateral) } \\
\text { brainstem and cerebellum } \\
\text { (bilateral), left occipital } \\
\text { lobe }\end{array}$ & $\begin{array}{l}\text { somnolence, dysarthria } \\
\text { reduced speech, initial } \\
\text { somnolence, semantic } \\
\text { paraphasias, perseverations }\end{array}$ \\
\hline Present case & $\mathrm{pf}, \mathrm{dm}, \mathrm{cm}$ & $\begin{array}{l}\text { vp, (Tmth) } \\
\text { (vlo) }\end{array}$ & $\begin{array}{l}\text { midbrain (left), } \\
\text { scarce minute lesions } \\
\text { in the cerebral } \\
\text { hemispheres, ansa } \\
\text { lenticularis, subthalamic } \\
\text { nucleus }\end{array}$ & $\begin{array}{l}\text { initial somnolence and } \\
\text { disorientation, anterograde } \\
\text { amnesia, non-fluent and } \\
\text { reduced speech, semantic } \\
\text { (+ phonemic) paraphasias } \\
\text { and parelexias, anomia, } \\
\text { impairment of verbal } \\
\text { memory, apathy }\end{array}$ \\
\hline
\end{tabular}

$\mathrm{pf}=$ parafascicular nucleus, $\mathrm{cm}=$ centromedian nucleus, $\mathrm{dm}=$ dorsomedial nucleus, $\mathrm{pu}=$ pulvinar, Tmth $=$ mamillo-thalamic tract $($ Vic d'Azyr), vlo = ventral lateral nucleus-oral part, vlm $=$ ventral lateral nucleus-medial part, vlc $=$ ventral lateral nucleus-caudal part, $\mathrm{vp}=$ ventral posterior nucleus 
and in our patient. The PC was directly involved by the infarct in one reported case ${ }^{10}$ and in our patient; degenerated or demyelinated in two cases ${ }^{81327}$; and appeared spared in one case. ${ }^{28}$ However, in the latter case, the efferent fibres that converge to the midline to form the PC were very probably involved as in cases with tumours apparently sparing the PC. ${ }^{29}$ The inputs involved in upgaze decussate in the PC, ${ }^{13161830}$ so that a unilateral lesion involving the PC and its laterally spreading fibres can probably give rise to an upgaze palsy, as in experiments in the monkey. ${ }^{31}$ However, no proven lesion limited to the PC has ever been reported in man.

The upgaze palsy did not spare the vestibular response. Involvement of the PC does not abolish the vestibular-induced upward movements, because the vestibular inputs involved in upgaze do not follow the PC and reach the oculomotor and trochlear nuclei, either directly from the vestibular nuclei, or indirectly from a descending pathway probably originating in the iC. ${ }^{13162732}$. The absence of upward deviation on oculocephalic manoeuvre thus probably corresponded to involvement of the $\mathrm{iC}$, as destruction of the fibres of the PC do not alter vestibulo-ocular reflexes and because no lesion of the ascending vestibulo-oculomotor fibres was present.

The eyes were permanently deviated downward. Sustained or intermittent downgaze has been reported in diffuse encephalopathies ${ }^{\mathbf{3 3}}$ and in intracranial hypertension. ${ }^{34}{ }^{35}$ Patients with a unilateral or bilateral thalamic haemorrhage may also show a downward deviation of the eyes, ${ }^{2636-38}$ but they also show intracranial hypertension. There is no report of sustained downgaze from a midbrain lesion without intracranial hypertension. In one case, ${ }^{1327}$ an intermittent downward deviation of the eyes was reported. It was proposed that this intermittent deviation could have been due to transient firing of neurons in the riMLF and $\mathrm{iC}$, from an interruption of ascending vestibulo-mesencephalic ${ }^{39}$ or descending corticomesencephalic inhibiting pathways. In our case, no significant lesion of the ascending vestibulooculomotor pathways was present. The riMLF and iC were involved, and these structures are thought to be major supranuclear centres involved in tonic vertical vestibular reflexes. ${ }^{16}{ }^{18}$ Especially, the iC seems to have some importance in the vertical semicircular canal vestibulo-ocular reflex and upward vestibuloocular movements. ${ }^{40}$ Involvement of this nucleus may have caused an imbalance in vestibulooculomotor regulation at the origin of the sustained downward deviation of gaze. Involvement of corticomesencephalic fibres, with imbalance in the tonic inputs that regulate vertical smooth pursuit ${ }^{42}$ seems more improbable. The localisation of these fibres is not known, and in the case 4 of Pierrot-Deseilligny et $a l,{ }^{13}$ where upgaze palsy was limited to smooth pursuit movements, no downward deviation was present.

Our patient showed aphasic disturbances with reduction of speech, decreased verbal fluency, naming difficulties, perseverations, semantic and less often phonemic paraphasias, semantic paralexias and disturbed spelling. Repetition was spared. Comprehension was only slightly impaired. The unilateral left thalamic infarct involved the intralaminar, dorsomedial, and ventral posterior nuclei of the thalamus, as well as the mamillo-tegmental tract, and a small portion of the posterior part of the ventral lateral nucleus. The cerebral hemispheres showed only scarce minute lesions in the central regions, which could not be responsible for the symptoms. The role of the thalamus in linguistic activities was initially discussed in stimulation and electro-coagulation of the left thalamus, with emphasis placed on the ventral lateral nucleus and the pulvinar. ${ }^{4143-46}$ Language disturbances have been reported in thalamic tumors $^{46-48}$ and haemorrhages, ${ }^{49-58}$ with delineation of clinical syndromes suggesting motor, sensory, or mixed transcortical aphasia. In thalamic infarction, detailed aphasiological studies have been made with CT correlations. ${ }^{59-67}$ Reduction of speech, anomia, perseverations and semantic paraphasias were the most frequent alterations. Involvement of the ventral lateral nucleus and pulvinar has been usually suggested, ${ }^{45465962-646869}$ and could be related to connections with the prerolandic (ventral lateral nucleus) and postrolandic (pulvinar) cortical speech areas. ${ }^{69} 70$

We have found 11 cases of infarction of the paramedian part of the left thalamus with pathologic confirmation in the literature (see table 3), either without mesencephalic infarction, ${ }^{371}$ or with unilateral $^{2671172}$ or bilateral $^{71}$ midbrain involvement. Among these cases, neuropsychological disturbances were mentioned only in three, being either a confusional state, ${ }^{71}$ or aphasic symptoms very similar to those showed by our patient. ${ }^{672}$ Involvement of the ventral lateral and dorsomedial nucleus with sparing of the pulvinar was present in one of the cases with speech disturbances, ${ }^{72}$ and no detailed topographical analysis was provided in the other. $^{6}$ Our case suggests that destruction of the pulvinar and ventral lateral nucleus may not be necessary. Among the nuclei of the medial and intralaminar formations, the dorsomedial nucleus might be incriminated, because of connections with Broca's area, Wernicke's area, and the gyrus supramarginalis. ${ }^{69}$ Disturbances of verbal memory have also been attributed to involvement of the left dorsomedial nucleus. ${ }^{65} 73-75$

Although an extensive assessment of memory was not realised, the findings in our patient suggested a 
marked anterograde amnesia, with inability to recall any recent event. Older events were better recalled. There were no confabulations. Amnesic syndromes from thalamic infarcts have initially been studied in cases with bilateral lesions, ${ }^{76-78}$ most often in the context of "thalamic dementia". ${ }^{12657778}$ In necropsied cases, involvement of the dorsomedial nuclei or of the mamillo-thalamic tract of Vicq d-Azyr has been emphasised, ${ }^{71}{ }^{78}$ but to our knowledge, there is no report of a case with a unilateral thalamic infarct and amnesia, which was pathologically studied. In cases with CT study, involvement of the dorsomedial nucleus, ${ }^{657375}$ ventral lateral nucleus, ${ }^{657375}$ or of the anterior formation and mamillo-thalamic tract ${ }^{65}$ has been suggested. In the 11 cases with a proven left paramedian infarction of the thalamus (see table 3), the memory was not studied. In our case, in the absence of lesion of the mamillo-thalamic tract and of the anterior formation the amnesic disturbances were probably caused by severe lesion of the dorsomedial nucleus.

Marked underutilisation of the right side of the body, with no spontaneous movement, abnormal placement of the upper limb, poor withdrawal to pain, and motor impersistence were present, suggesting motor hemineglect. ${ }^{79}$ Motor neglect from a thalamic lesion has been attributed to involvement of the ventral lateral nucleus, ${ }^{8081}$ of the centromedian and parafascicular nuclei, ${ }^{82}$ or of the posterior part of the thalamus and pulvinar. ${ }^{83}$ No pathologic confirmation was provided in the latter two reports. A case with a right thalamic haemorrhage was necropsied, ${ }^{84}$ but detailed anatomical data were not provided. Our case may favour the theory of Watson et $a l,{ }^{82}$ because the centromedian and parafascicular nuclei were destroyed, whereas the ventral lateral nucleus showed only minor changes and the pulvinar was spared. The motor neglect may have been due to global dysfunction of hemispheric activation, related to involvement of these nuclei and of inputs from the mesencephalic reticular formation. ${ }^{82}$ Except in one report, ${ }^{80}$ all series showed that thalamic neglect is more frequently caused by right than by left-sided lesions. However, our case shows that involvement of the left intralaminar formation may cause motor neglect on the right side of the body. Involvement of the mesencephalic reticular formation has also been suggested in some forms of unilateral neglect. ${ }^{85}$ However, in our case, the unimodal aspect of the neglect suggests that the lesion of the upper mesencephalic reticular formation was not responsible.

The authors thank H Van der Loos, MD, University Department of Anatomy, Lausanne, for his helpful comments.

\section{References}

${ }^{1}$ Claude H, Loyez Mlle. Ramollissement du noyau rouge. Rev Neurol (Paris) 1912;23:40-51.

${ }^{2}$ Freund SC. Zur Klinik und Anatomie der vertikalen Blicklähmung. Neurol Centralbl 1913;32:1215-29.

${ }^{3}$ Chiray M, Foix C, Nicolesco J. Hémitremblement du type de la sclérose en plaques par lésion rubro-thalamosousthalamique. Syndrome de la région supéro-externe du noyau rouge avec atteinte silencieuse ou non du thalamus. Ann Méd (Paris) 1923;14:173-91.

${ }^{4}$ Sigwald J, Monnier M. Syndrome thalamohypothalamique avec hémitremblement (ramollissement du territoire artériel thalamo-perforé). Rev Neurol (Paris) 1936;66:616-31.

${ }^{5}$ Schuster P. Beiträge zur Pathologie des Thalamus opticus I. Arch Psychiat Nervenkrank 1936;105:358-432.

${ }^{6}$ Molnàr L. Die lokaldiagnostische Bedeutung der Vertikalen Blicklähmung; Beiträge zur Symptomatologie und Faseranatomie des meso-diencephalen Utbergangsgebietes. Arch Psychiat Nervenkrank 1959;198:523-34.

${ }^{7}$ Gruner JE, Feuerstein J. Troubles de la conscience et tronc cérébral. Corrélations anatomo-cliniques. In: Clinical experiences in brain stem disorders (Inhàsz IL ed.) Acta 25 Conventus Neuropsychiatricus et EEG Hungarici, Vàllalat, Budapest 1966, 293-6.

${ }^{8}$ Hatcher MA, Klintworth GK. The sylvian acqueduct syndrome. Arch Neurol 1966;15:215-22.

9 Jakimowicz K, Stefanko S, Pajak B. Ramollissements du thalamus dans le territoire des pédicules artériels venant de la cérébrale postérieure. Acta Med Pol 1968;9: 447-54.

${ }^{10}$ Christoff N. A clinicopathologic study of vertical eye movements. Arch Neurol 1974;31:1-8.

${ }^{11}$ Sieben G, de Reuck J, Van der Eecken H. Thrombosis of the mesencephalic artery. A clinico-pathological study of two cases and its correlation with the arterial vascularisation. Acta Neurol Belg 1977;77:151-62.

12 Castaigne P, Buge A, Cambier J, Escourolle R, Brunet P, Degos JD. Démence thalamique d'origine vasculaire par ramollissement bilatéral limité au territoire du pédicule rétro-mamillaire (à propos de 2 observations anatomo-cliniques). Rev Neurol (Paris) 1966;114: 89-108.

${ }^{13}$ Pierrot-Deseilligny C, Chain F, Gray F, Serdaru M, Escourolle R, Lhermitte F: Parinaud's syndrome. Electro-oculographic and anatomical analyses of six vascular cases with deductions about vertical gaze organization in the premotor structures. Brain 1982;105:667-96.

${ }^{14}$ Eager RP. Selective staining of degenerating axons in the central nervous system by a simplified method: spinal cord projections to external cuneate and inferior olivary nuclei in the cat. Brain Res 1970;22:137-41.

${ }^{15}$ Grafe MR, Leonard CM. Successful silver impregnation of degenerating axons after long survivals in the human brain. J Neuropathol Exp Neurol 1980;39:555-74.

${ }^{16}$ Bender MB. Brain control of conjugate horizontal and vertical eye movements. A survey of the structural and functional correlates. Brain 1980;103:23-69.

${ }^{17}$ Trojanowski JQ, Lafontaine MH. Neuroanatomical correlates of selective downgaze paralysis. $J$ Neurol Sci 1981;52:91-101.

${ }^{18}$ Büttner-Ennever JA, Büttner U, Cohen B, Baumgartner 
G: Vertical gaze paralysis and the rostral interstitial nucleus of the medial longitudinal fasciculus. Brain 1982;105: 125-49.

${ }^{19}$ Henoch EH. Tuberkulose der Corpora quadrigemina. Berlin Klin Wochschr 1984;1:125-7.

${ }^{20}$ Parinaud H. Paralysie des mouvements associés des yeux. Arch Neurol 1883;5:145-72.

${ }^{21}$ Nashold BS Jr, Seaber JH. Defects of ocular motility after stereotactic midbrain lesions in man. Arch Ophthalmol 1972;88:245-8.

${ }^{22}$ Seaber JH, Nashold BS Jr: Comparison of ocular motor effects of unilateral stereotactic midbrain lesions in man. Neuro-ophthalmol 1980;1:95-8.

${ }^{23}$ Smith MS, Laguna JF. Upward gaze paralysis following unilateral pretectal infarction. Arch Neurol 1981; 38:127-9.

${ }^{24}$ Reich F. Herd im Thalamus opticus. Neurol Centralbl 1904;14:662.

${ }^{25}$ Van Gehuchten P. Syndrome de Parinaud. Etude anatomique. J Belge Neurol Psychiat 1940;40:126-33.

${ }^{26}$ Környey A: Blickstörungen bei vasculären Herden des meso-diencephalen Übergangsgebietes. Arch Psychiat Nervenkrank 1959;198:535-43.

${ }^{27}$ Serdaru M, Gray F, Lyon-Caen O, Escourolle R, Lhermitte F. Syndrome de Parinaud et déviation tonique verticale du regard. Trois observations anatomocliniques. Rev Neurol (Paris) 1982;138:601-17.

${ }^{28}$ Balthasar K, Hopf A: Die Freund-Vogt'sche Herdbildung bei supranuklearer Heberlähmung der Augen mit Lidretraktion. Dtsche Zt Nervenheilk 1966;189:275-96.

${ }^{29}$ Moffié D, Ongerboer de Visser BW, Stefanko SZ. Parinaud's syndrome. J Neurol Sci 1983;58:175-83.

${ }^{30}$ Bogousslavsky J, Regli F. Upgaze palsy and monocular paresis of downward gaze from ipsilateral thalamomesencephalic infarction: A vertical "one-and-a-half" syndrome. J Neurol 1984;231:43-45.

${ }^{31}$ Pasik P, Pasik T, Bender MB. The pretectal syndrome in monkeys. I. Disturbances of gaze and body posture. Brain 1969;92:521-34.

${ }^{32}$ Pola J, Robinson DA. Oculomotor signals in medial longitudinal fasciculus of the monkey. $J$ Neurophysiol 1978;41:245-59.

${ }^{33}$ Keane JR, Rawlinson DG, Lu AT. Sustained downward deviation. Two cases without structural pretectal lesions. Neurology (Minneap) 1976;26:594-5.

${ }^{34}$ Lundberg N: Continuous recording and control of ventricular fluid pressure in neurosurgical practice. Acta Psychiatr Neurol Scand 1960;36 (suppl):1-193.

${ }^{35}$ Hoyt W, Daroff RB. Supranuclear disorders of ocular control systems in man. In: The control of eye movements (Bach y Rita P, Collins CC, Hyde JE, eds), New York, Academic Press 1971:175-235.

${ }^{36}$ Fisher CM. Some neuro-ophthalmologic observations. $J$ Neurol Neurosurg Psychiatry 1967;30:383-92.

${ }^{37}$ Lapresle J, Said G. Déviation forcée des yeux vers le bas et en dedans et mouvements oculaires périodiques au cours d'une hémorragie anévrysmale de la calotte mésencéphalique. Rev Neurol (Paris) 1977;133:497-503.

${ }^{38}$ Gilner LI, Avin B. A reversible ocular manifestation of thalamic hemorrhage. A case report. Arch Neurol 1977;34:715-6.

${ }^{39}$ Tarlov E. Anatomy of the two vestibulo-oculomotor projection systems. In: Brodal A, Pompeiano O, eds. Basic aspects of central vestibular mechanisms Amsterdam, Elsevier 1972:471-91.

${ }^{40}$ Anderson JH. Behavior of the vertical canal VOR in normal and INC-lesioned cats. In: Fuchs AF, Becker W, eds. Progress in Oculomotor Research Amsterdam, Elsevier 1981:396-401.

${ }^{41}$ Guiot G, Hertzog E, Rondot P, Molina P. Arrest or acceleration of speech evoked by thalamic stimulation in the course of stereotaxic procedures for parkinsonism. Brain 1961;84:363-9.

${ }^{42}$ Barontini F, Simonetti C, Ferranini F, Sita D. Persistent upward eye deviation. Report of two cases. Neuroophthalmol 1983;3:217-24.

${ }^{43}$ Krayenbühl H, Siegfried J, Kohenof M, Yasargil MG. Is there a dominant thalamus? Confin Neurol 1965; 26:246-9.

${ }^{44}$ Bell DS. Speech function of the thalamus inferred from the effects of thalamotomy. Brain 1968;91:619-38.

${ }^{45}$ Ojemann GA, Fedeo P, Van Buren JM. Anomia from pulvinar and subcortical parietal stimulation. Brain 1968;91:99-117.

${ }^{46}$ Ojemann GA, Ward AA. Speech representation in the ventro-lateral thalamus. Brain 1971;91:99-117.

${ }^{47}$ Smythe GE, Stern K. Tumors of the thalamus. A clinicopathological study. Brain 1938;61:339-74.

${ }^{48}$ McKissock W, Paine KWE. Primary tumors of the thalamus. Brain 1958;81:41-63.

${ }^{49}$ Cheek WR, Taveras J: Thalamic tumors. J Neurosurgery 1966;24:505-13.

${ }^{50}$ Bugiani O, Conforto C, Sacco G. Aphasia in thalamic hemorrhage. Lancet 1969;i:1052.

${ }^{51}$ Ciemens VA. Localized thalamic hemorrhage. A cause of aphasia. Neurology (Minneap) 1980;20:776-82.

${ }^{52}$ Mohr JP, Watters WC, Ducan GW. Thalamic hemorrhage and aphasia. Brain Lang 1975;2:3-17.

${ }^{53}$ Luria AR. A quasi-aphasic speech disturbance in lesions of the deep structures of the brain. Brain Lang 1977; 4:432-59.

${ }^{54}$ Reynolds AF, Turner PT, Harris AB, Ojemann GA, Davis LE. Left thalamic hemorrhage with dysphasia. Brain Lang 1979;7:62-73.

55 Cappa SF, Vignolo LA. "Transcortical" features of aphasia following left thalamic hemorrhage. Cortex 1979;15:121-30.

${ }^{56}$ Alexander MP, Lo Verme SR Jr. Aphasia after left hemispheric intracerebral hemorrhage. Neurology (Minneap) 1980;30:1193-202.

${ }^{57}$ Assal G, Lanares J. Syndrome amnésique transitoire lors d'un hématome thalamique gauche. Congrès de psychiatrie et de neurologie, Barcelone 1982:265-70.

${ }^{58}$ Papagno C, Guidotti M. A case of aphasia following left thalamic hemorrhage. Eur Neurol 1983;22:93-95.

${ }^{59}$ Elghozi D, Strube E, Signoret JL, Cambier J, Lhermitte F. Quasi-aphasie lors de lésions du thalamus. Relation du trouble du langage et de l'activation élective de l'hémisphère gauche dans 4 observations de lésions thalamiques gauches et droites. Rev Neurol (Paris) 1978;134:557-74.

${ }^{60}$ Mazaux JM, Orgogozo JM, Henry P, Loiseau P. Troubles du langage au cours des lésions thalamiques. Etude par le test de Goodglass et Kaplan. Rev Neurol (Paris) 
1979;135:59-64.

${ }^{61}$ Demeurisse G, Derouck M, Coekaerts MJ, et al. Study of two cases of aphasia by infarction of the left thalamus. Acta Neurol Belg 1979;79:450-9.

${ }^{62}$ Cohen JA, Gelfer CE, Sweet RD. Thalamic infarction producing aphasia. Mt Sinai J Med (NY) 1980; 47:398-404.

${ }^{63}$ Archer CR, Ilinsky IA, Goldfader PR, Smith KR Jr. Aphasia in thalamic stroke: CT stereotactic localization. J Comp Assist Tomogr 1981;5:427-32.

${ }^{64}$ McFarling D, Rothi LJ, Heilman KM. Transcortical aphasia ischaemic infarcts of the thalamus: a report of two cases. J Neurol Neurosurg Psychiatry 1982; 45:107-12.

${ }^{65}$ Michel D, Laurent B, Foyatier N, Blanc A, Portafaix M. Infarctus thalamique paramédian gauche. Etude de la mémoire et du langage. Rev Neurol (Paris) 1982; 138:533-50.

${ }^{66}$ Graff-Radford NR, Eslinger PJ, Damasio AR, Yamada T. Non-hemorrhagic infarction of the thalamus. Behavioral, anatomic and physiologic correlates. Neurology (Cleveland) 1984;34:14-23.

${ }^{67}$ Gorelick PB, Hier DB, Benevento L, Levitt S. Aphasia after left thalamic infarction. Arch Neurol 1984; 41:1296-8.

${ }^{68}$ Ojemann GA. Subcortical language mechanisms. In: Neurolinguistics Whitaker H, Whitaker HA, eds. Vol 1, New York Academic Press, 1976:103-38.

${ }^{69}$ Van Buren JM, Borke RC. Alterations in speech and the pulvinar. Brain 1979;92:255-84.

${ }^{70}$ Roch Lecours A, Lhermitte F. L'aphasie. Paris Flammarion, 1979:193-222.

${ }^{71}$ Castaigne P, Lhermitte F, Buge A, Escourolle R, Hauw JJ, Lyon-Caen O. Paramedian thalamic and midbrain infarcts: clinical and neuropathological study. Ann Neurol 1981;10:127-48.

${ }^{72}$ Davous P, Bianco C, Duval-Lota AM, De Recondo J, - Vedrenne C, Rondot P. Aphasie par infarctus thalamopédonculaire gauche. Observation anatomo-clinique. Rev Neurol (Paris) 1984;140:711-9.
${ }^{73}$ Squire LR, Moore RY: Dorsal thalamic lesion in a noted case of human memory dysfunction. Ann Neurol 1979;6:503-6.

${ }^{74}$ Speedie LJ, Heilman KM. Anterograde memory deficits for visuospatial material after infarction of the right thalamus. Arch Neurol 1983;40:183-6.

${ }^{75}$ Goldenberg G, Wimmer A, Maly J. Amnesic syndrome with a unilateral thalamic lesion: a case report. $J$ Neurol 1983;229:79-86.

${ }^{76}$ Schott B, Mauguière F, Laurent B, Serclerat O, Fischer C. L'amnésie thalamique. Rev Neurol (Paris) 1980; 136:117-30.

${ }^{77}$ Guberman A, Stuss D. The syndrome of bilateral paramedian thalamic infarction. Neurology (NY) 1983; 33:540-6.

${ }^{78}$ Poirier J, Barbizet J, Gaston A, Meyrignac C. Démence thalamique. Lacunes expansives du territoire thalamomésencéphalique paramédian. Hydrocéphalie par sténose de l'acqueduc de sylvius. Rev Neurol (Paris) 1983;139:349-58.

${ }^{79}$ Laplane D, Degos JD. Motor neglect. J Neurol Neurosurg Psychiatry 1983;46:152-8.

${ }^{80}$ Zoll JG. Transient anosognosia associated with thalamotomy: is it caused by proprioceptive loss? Confin Neurol 1969;31:48-55.

${ }^{81}$ Laplane D, Escourolle R, Degos JD, Sauron B, Massiou $\mathrm{H}$. La négligence motrice d'origine thalamique. A propos de deux cas. Rev Neurol (Paris) 1982;138:201-11.

${ }^{82}$ Watson RT, Valenstein EV, Heilman KM. Thalamic neglect. Possible role of the medial thalamus and nucleus reticularis in behaviour. Arch Neurol 1981;38:501-6.

${ }^{83}$ Schott B, Laurent B, Mauguière F, Chazot G. Négligence motrice par hématome thalamique droit. Rev Neurol (Paris) 1981;137:447-55.

${ }^{84}$ Watson RT, Heilman KM. Thalamic neglect. Neurology (Minneap) 1979;29:690-4.

${ }^{85}$ Watson RT, Heilman KM, Miller BD, King FA. Neglect after mesencephalic reticular formation lesions. Neurology (Minneap) 1974;24:294-8. 